\title{
CARDIAC EVALUATION IN NEWBORNS: AN ECHOCARDIOGRAPHY BASED STUDY
}

\author{
Muhammad Sohail Arshad ${ }^{1}$, Waqas Shakir ${ }^{1}$, Hafiz Muhammad Anwar-ul-Haq ${ }^{1}$, Mudasser Adnan ${ }^{1}$, \\ Munir Ahmad ${ }^{1}$
}

1 Children's Hospital \& The Institute of Child Health, Multan

Address for Correspondence:

Munir Ahmad

Department of Neonatology, Children's Hospital \& The Institute of Child Health, Multan, Pakistan

Emails: dr.munir.ahmad2@gmail.com

\section{Contribution}

MSA conceived the idea and designed the study. Data collection and manuscript writing was done by MSA, WS, HMAH, MA, and MA. All the authors contributed equally to the submitted manuscript.

All authors declare no conflict of interest.

This article may be cited as: Arshad MS, Shakir W, Haq HMA, Adnan M, Ahmad M. Cardiac Evaluation in Newborns: An Echocardiography Based Study. Pak Heart J 2021;54(01):25-29. https://doi.org/10.47144/phi.v54i1.2060

\section{ABSTRACT}

Objective: To evaluate the cardiac status of newborns in terms of structural and functional heart diseases.

Methodology: This descriptive study was conducted at Paediatric Cardiology Department of "The Children's Hospital and The Institute of Child Health", Multan, Pakistan, from January 2017 to December 2019. Neonates aged 0-28 days and referred for echocardiographic evaluation were enrolled. Diagnostic findings were confirmed with the assistance of echocardiography. We were focused on analyzing total number and types of heart diseases along with gender distribution during the study period.

Results: During the study period, a total of 2729 newborns were evaluated. We noted $1523(55.8 \%)$ newborns as structurally and functionally normal, $866(31.7 \%)$ had congenital heart disease, $69(2.5 \%)$ duct dependent lesions, $248(9.1 \%)$ persistent pulmonary hypertension and $23(0.8 \%)$ left ventricular (LV) dysfunction but with structurally normal heart. Newborns with LV dysfunction might have hypoxic myocardial damage, metabolic derangements or acute myocarditis. Ventricular Septal Defect (VSD) followed by Patent Ductus Arteriosus (PDA) and Atrial Septal Defect (ASD) were the most frequent types of acyanotic CHD observed in $248(28.2 \%), 171(19.7 \%)$ and $100(11.5 \%)$ neonates respectively while Tetralogy of Fallot (TOF) was the most common type of cyanotic CHD 74 $(8.5 \%)$.

Conclusion: VSD followed by PDA, ASD and TOF were the most common types of CHD among neonates. Diagnosis of congenital heart defects in the early age is pointing towards improvement in healthcare facilities.

Keywords: Congenital heart disease, echocardiography, ventricular septal defect. 


\section{INTRODUCTION}

"A gross structural abnormality of the heart or intrathoracic great vessels that is actually or potentially of functional significance" was labeled as congenital heart disease (CHD) by Mitchell SC and Colleagues. ${ }^{1}$ Congenital heart defects are considered to be a global health issue and the most frequent cause of congenital anomalies contributing around $28.0 \%$ of all congenital anomalies while incidence of congenital heart defects is estimated to be between 3 to 10/1000 live births, however, some researchers estimated this incidence to be as high as $17.5 / 1000$ live births. ${ }^{2,3}$

Among developing countries like Pakistan, burden of congenital heart defects is mounting every passing day due to rise in risk factors and causative factors. In some regional community based findings, it has been revealed that more than $30 \%$ of congenital heart defects cases require critical interventions during $1^{\text {st }}$ year of life and majority come to cardiac healthcare units with complications. ${ }^{4}$ Data from developed countries have shown an increase in the survival rates from $20-80 \%$ in adult CHD cases because of early detection and appropriate treatment modalities. ${ }^{5,6}$

Recent data from Pakistan have found ventricular septal defect (VSD) to be the most prevalent type of acyanotic heart lesion (27\%) among children with CHD whereas Tetralogy of Fallot (TOF) was seen to be the commonest types of cyanotic heart defect noted in $10.9 \%$ cases. $^{7}$ In the last 5 years, to the best of our knowledge, no study has been conducted specifically to find out the pattern or types of CHD in neonates while data from 2010 suggested VSD in $31.0 \%$ followed by atrial septal defect (ASD) in $22.9 \%$ and patent ductus arteriosus (PDA) in $15.0 \%$ of neonates with CHD. ${ }^{8}$

In the last few decades, significant progress has been made in improving the screening and treatment of congenital heart defects especially in the developed countries. Understanding the patterns of congenital heart defects is of great interest for the researchers and policymakers worldwide as knowing about the disease types and its burden is of huge importance. Acknowledging differences in different patterns and trends in congenital heart defects can lead to better insights to enhance the current practices in centers catering these cases. As no recent data elaborates frequency or patterns of congenital heart defects in neonates in Pakistan, this study was aimed at to evaluate the cardiac status of newborns in terms of structural and functional heart diseases.

\section{METHODOLOGY}

This descriptive study was conducted at Paediatric Cardiology Department of "The Children's Hospital and The Institute of Child Health", Multan, Pakistan, from January 2017 to December 2019. Approval from "Institutional Ethical Committee" was taken for this study (No.203, dated: 15/01/2018).

All newborns from birth to 28 days of age, referred for echocardiographic evaluation were enrolled. Reason for referral included $\mathrm{O}_{2}$ dependency, cyanosis, murmur, any other associated anomalies (e.g. VACTER, VACTRAL, cleft lip and palate, TEF, TORCH) and family history of CHD or maternal diabetes mellitus. Newborns who could not be sent for echocardiographic evaluation were excluded from this study.

Echocardiography among all cases was done by consultant Paediatric Cardiologist. Newborns with patent foramen ovale and small PDA were considered normal as these are age related findings. Likewise, babies with bicuspid aortic valve without any aortic stenosis or aortic regurgitation and babies with mild to moderate pulmonary hypertension were also considered as normal. In case of a combination or multiple cardiac lesions in a patient, the major lesion was taken as the main diagnosis. We were focused on analyzing total number and types of heart diseases along with gender distribution of cases. All the study data was recorded on a predesigned proforma. Data was handled and analyzed using SPSS version 26.0. Data was represented in terms of frequency and percentage.

\section{RESULTS}

During the study period from 2017 to 2019 , a total of 2729 newborns were evaluated. Table number 1 is showing diagnostic findings of newborns evaluated during the study period. Out of these 2729 cases, $1523(55.8 \%)$ were structurally and functionally normal, $866(31.7 \%)$ had congenital heart disease, 
69 (2.5\%) duct dependent lesions, 248 (9.1\%) persistent pulmonary hypertension (these patients did not have congenital heart disease) and 23 $(0.8 \%)$ left ventricular (LV) dysfunction but with structurally normal heart. Newborns with LV dysfunction might have hypoxic myocardial damage or metabolic derangements or acute myocarditis.

Table 1: Diagnostic Findings of Newborns Evaluated During the Study Period $(n=2729)$

\begin{tabular}{|l|c|}
\hline Diagnostic Findings & Number (\%) \\
\hline Normal & $1523(55.8 \%)$ \\
\hline Structural Heart Disease & \\
\hline Duct Dependent CHD & $69(2.5 \%)$ \\
\hline Non-Duct Dependent CHD & $866(31.7 \%)$ \\
\hline Functional Heart Disease & \\
\hline $\begin{array}{l}\text { Persistent Pulmonary } \\
\text { Hypertension }\end{array}$ & $248(9.1 \%)$ \\
\hline \begin{tabular}{l} 
Dysfunctioning LV \\
\hline
\end{tabular} & $23(0.8 \%)$ \\
\hline
\end{tabular}

We observed CHDs among 866 newborns. VSD followed by PDA and ASD were the most frequent types of acyanotic CHD observed in 248 (28.2\%), $171(19.7 \%)$ and $100(11.5 \%)$ neonates respectively while TOF was the most common type of cyanotic CHD found among 74 (8.5\%) neonates. Table number 2 is showing distribution of various types of CHDs noted among studied neonates with regards to gender. Among $866 \mathrm{CHDs}$ cases, 666 were having acyanotic CHD while 200 had cyanotic CHDs.

\section{Table 2: Types of Congenital Heart Disease with Regards to Gender Distribution}

\begin{tabular}{|l|c|c|c|}
\hline $\begin{array}{l}\text { Types of } \\
\text { CHD }\end{array}$ & $\begin{array}{c}\text { Number } \\
(\%)\end{array}$ & Male (\%) & $\begin{array}{c}\text { Female } \\
(\%)\end{array}$ \\
\hline $\begin{array}{l}\text { Tetralogy of } \\
\text { Fallot }\end{array}$ & $74(8.5 \%)$ & $\begin{array}{c}38 \\
(51.3 \%)\end{array}$ & $\begin{array}{c}36 \\
(48.7 \%)\end{array}$ \\
\hline $\begin{array}{l}\text { TGA with VSD } \\
\text { with PS }\end{array}$ & $19(2.2 \%)$ & $\begin{array}{c}11 \\
(57.9 \%)\end{array}$ & $8(42.1 \%)$ \\
\hline $\begin{array}{l}\text { TGA with VSD } \\
\text { with PH }\end{array}$ & $12(1.4 \%)$ & $7(58.3 \%)$ & $5(41.7 \%)$ \\
\hline VSD & 248 & 135 & 113 \\
\hline ASD & $(28.2 \%)$ & $(54.4 \%)$ & $(45.6 \%)$ \\
\hline Complete & 100 & 52 & 48 \\
AVSD & $34(3.9 \%)$ & $(50.0 \%)$ & $(50.0 \%)$ \\
\hline PDA & 171 & 91 & 80 \\
\hline
\end{tabular}

\begin{tabular}{|c|c|c|c|}
\hline $\begin{array}{l}\text { Pulmonary } \\
\text { atresia }\end{array}$ & $19(2.2 \%)$ & $\begin{array}{c}10 \\
(52.6 \%)\end{array}$ & 9 (47.4\%) \\
\hline $\begin{array}{l}\text { Tricuspid } \\
\text { atresia }\end{array}$ & $5(0.6 \%)$ & $3(60.0 \%)$ & 2 (40.0\%) \\
\hline $\begin{array}{l}\text { Univentricular } \\
\text { Heart }+ \\
\text { Complex CHD }\end{array}$ & 31 (3.6\%) & $\begin{array}{c}17 \\
(54.8 \%)\end{array}$ & $\begin{array}{c}14 \\
(45.2 \%)\end{array}$ \\
\hline $\begin{array}{l}\text { Aortic } \\
\text { Stenosis }\end{array}$ & 31 (3.6\%) & $\begin{array}{c}16 \\
(51.6 \%)\end{array}$ & $\begin{array}{c}15 \\
(48.4 \%)\end{array}$ \\
\hline $\begin{array}{l}\text { Pulmonary } \\
\text { Stenosis }\end{array}$ & 35 (4.0\%) & $\begin{array}{c}19 \\
(54.3 \%)\end{array}$ & $\begin{array}{c}16 \\
(45.7 \%)\end{array}$ \\
\hline $\begin{array}{l}\text { Coarctation of } \\
\text { Aorta }\end{array}$ & 47 (5.4\%) & $\begin{array}{c}28 \\
(59.6 \%)\end{array}$ & $\begin{array}{c}19 \\
(40.4 \%)\end{array}$ \\
\hline $\begin{array}{l}\text { Cardiac } \\
\text { TAPVC }\end{array}$ & $1(0.1 \%)$ & $0(0 \%)$ & $1(100 \%)$ \\
\hline $\begin{array}{l}\text { Supra cardiac } \\
\text { TAPVC }\end{array}$ & $1(0.1 \%)$ & 1 (100\%) & $0(0 \%)$ \\
\hline $\begin{array}{l}\text { Ebstein } \\
\text { Anomaly }\end{array}$ & 14 (1.6\%) & $8(57.1 \%)$ & 6 (42.9\%) \\
\hline Others & 24 (2.8\%) & $\begin{array}{c}14 \\
(58.3 \%)\end{array}$ & $\begin{array}{c}10 \\
(41.7 \%)\end{array}$ \\
\hline Total & $\begin{array}{c}866 \\
(100 \%)\end{array}$ & $\begin{array}{c}467 \\
(53.9 \%)\end{array}$ & $\begin{array}{c}399 \\
((46.1 \%)\end{array}$ \\
\hline
\end{tabular}

TGA with intact septum were the most common duct dependent lesion noted among 24 (34.8\%) neonates followed by critical coarctation of aorta 17 (24.6\%). Table number 3 shows distribution of various types of duct dependent lesions found among neonates.

Table 3: Distribution of Duct Dependent Lesions

\begin{tabular}{l|c|c|c|}
\hline $\begin{array}{l}\text { Duct Dependent } \\
\text { Lesions }\end{array}$ & Total & Male & Female \\
\hline $\begin{array}{l}\text { TGA with intact } \\
\text { septum }\end{array}$ & 24 & 13 & 11 \\
Critical & $(34.8 \%)$ & $(54.2 \%)$ & $(45.8 \%)$ \\
Coarctation of & 17 & 10 & 7 \\
Aorta & $(24.6 \%)$ & $(58.8 \%)$ & $(41.2 \%)$ \\
\hline $\begin{array}{l}\text { Critical Aortic } \\
\text { stenosis }\end{array}$ & $6(8.7 \%)$ & 3 & 3 \\
\hline $\begin{array}{l}\text { Pulmonary atresia } \\
\text { with intact septum }\end{array}$ & $(21.7 \%$ & $(46.7 \%)$ & $(50.0 \%)$ \\
\hline Hypoplastic Left & 7 & 3 & 8 \\
Heart & $(10.1 \%)$ & $(42.9 \%)$ & $(57.1 \%)$ \\
\hline Total & 69 & 36 & 33 \\
\hline & $(100 \%)$ & $(52.2 \%)$ & $(47.8 \%)$ \\
\hline
\end{tabular}

\section{DISCUSSION}

The exact prevalence of CHD at the time of birth has not yet been estimated globally which could further elaborate the influence of various environmental as well as genetic risk factors on the prevalence of 


\section{Cardiac Evaluation in Newborns: An Echocardiography Based Study}

CHDs among different geographies of the world. ${ }^{9} \mathrm{CHDs}$ can involve the chamber or valves inside the heart or the blood vessels which carry blood to and from the heart. The defects can be in isolation or in combination with different defects. Physiologically they can be divided broadly into cyanotic and acyanotic heart defects. ${ }^{10}$ Acyanotic heart defects can remain asymptomatic throughout life but some of them warrant early intervention. CHDs vary from simple defects without any symptoms to more complex lesions presenting as severe, life-threatening conditions. In contrast to developed countries, in parts of the developing world, access to timely treatment remains largely unavailable for CHDs. Better diagnostic facilities, early intervention and improved surgical outcomes have led to a change in spectrum of patients with congenital heart defects. ${ }^{11}$ This improved survival as also led to development of new specialties like Grown up with congenital heart defects (GUCHD).

We notice a male predominance (53.9\%) among neonates with CHDs. Previous local data has revealed $55.3 \%$ of the cases with heart defects to be male children. ${ }^{12}$ Others have also found similar findings revealing male predominance among $\mathrm{CHD}$ cases $^{7}$ while data from India also recorded $66 \%$ of $\mathrm{CHD}$ cases to be male. ${ }^{13} \mathrm{We}$ noted that VSD followed by PDA and ASD were the most frequent types of acyanotic CHD observed in $28.2 \%, 19.7 \%$ and $11.5 \%$ neonates respectively while TOF was the most frequent type of cyanotic CHD found among $8.5 \%$ neonates. Hussain $S$ et al in a local study evaluating neonates with CHD noted VSD to be the commonest type of CHD (31.0\%) followed by ASD (22.9\%), PDA (14.9\%) and TOF (6.9\%). ${ }^{14}$ Farooqui $R$ et al also noted VSD and PDA to be the most frequent forms of CHDs among neonates which is correlating well with the current data. VSD has been found the most frequent CHD type in Pakistan. ${ }^{8}$ Meshram RM and Gajimwar VS from India in a recent research noted VSD (30.1\%) to form majority of CHD cases while ASD (20.7\%), TOF $(16.1 \%)$ and PDA $(10.2 \%)$ were the other most frequent types of CHDs. ${ }^{15}$ Most of the other regional studies also report similar patterns of CHDs. ${ }^{16-18}$ Differences in patterns and frequencies of $\mathrm{CHD}$ types may be credited to differences in detection methods, standards of healthcare care and variations in genetic and environmental factors. ${ }^{19,21}$ We were unable to record any complications of CHD among enrolled study participants but growth failure and congestive cardiac failure are some of the most common ones. Inpatient case fatality rate among neonates with CHD is around 19\% while majority of the deaths have been attributed to complex $\mathrm{CDH}$, refractory congestive cardiac failure and sepsis. ${ }^{15,22}$ All murmurs should be carefully screened unless thought to be physiological. CHD requires regular monitoring to allow optimum growth and development.

Being the $1^{\text {st }}$ study from a Pediatric Cardiology Unit from South Punjab is one of the major significance of this study but there is a need to form National Registry for these patients. We need more and more cardiac surgery facilities capable of performing surgeries in infancy among CHD cases requiring correction/intervention.

Our study had few limitations as well. We were unable to record typical patterns of presentation and comorbidities in our cases. We could not gather any follow up data about functional and growth limitations of these patients.

\section{CONCLUSION}

VSD followed by PDA, ASD and TOF were the most common types of CHD among neonates. Diagnosis of congenital heart defects in the early age is pointing towards improvement in healthcare facilities. Population based studies on a large scale are needed to estimate the burden and pattern of congenital heart defects in Pakistan.

\section{REFERENCES}

1. Mitchell SC, Korones SB, Berendes HW. Congenital heart disease in 56, 109 births. Incidence and natural history. Circulation. 1971;43:323-32.

2. Qazi M, Saqib N. Spectrum of congenital heart disease in neonates in a tertiary care centre of Northern India. Int $\mathrm{J}$ Contemp Pediatr. 2018;5:1505-8.

3. Dolk H, Loane M, Garne E. For the European Surveillance of Congenital Anomalies (EUROCAT) working Group. Congenital heart defects in Europe:prevalence and perinatal mortality, 2000-2005. Circulation. 2011;123:8419.

4. Zeng Z, Zhang H, Liu F, Zhang N. Current diagnosis and treatments for critical congenital heart defects. Exp Ther Med. 2016;11(5):15504.

5. Bhardwaj R, Rai SK, Yadav AK, Lakhotia S, Agrawal D, Kumar A, et al. Epidemiology of congenital heart disease in India. Congenit Heart Dis. 2015;10(5):437-46. 


\section{Cardiac Evaluation in Newborns: An Echocardiography Based Study}

6. Saxena A, Mehta A, Sharma M, Salhan S, Kalaivani M, Ramakrishnan $S$, et al. Birth prevalence of congenital heart disease: a crosssectional observational study from North India. Ann Pediatr Cardiol.2016;9(3):205-9.

7. Sehar T, Sheikh AM, Kanwal A. To identify pattern of congenital heart diseases in a newly Developed tertiary care unit. Pak Armed Forces Med J. 2019;69(4):831-6.

8. Farooqui R, Haroon UF, Niazi A, Niazi NM. Congenital Heart Diseases in Neonates. J Rawal Med Coll ; 2010;14(1):31-2.

9. Wu W, He J, Shao X. Incidence and mortality trend of congenital heart disease at the global, regional, and national level, 1990-2017. Medicine (Baltimore). 2020;99(23):e20593.

10. Zahid SB, Jan AZ, Ahmed S, Achakzai $H$. Spectrum of congenital heart disease in children admitted for cardiac surgery at Rehman Medical Institute, Peshawar, Pakistan. Pak J Med Sci. 2013;29(1):173-6.

11. Mughal, A., Tousif, R., Alamgir, A, Jalal, A. Pattern of un-operated Grown Up Congenital Heart (GUCH) patients presenting to a Tertiary Care Cardiac Institute of Punjab. Pak J Med Sci. 2019;35(4):1066.

12. Mohammad N, Shaikh S, Memona S, Das H. Spectrum of heart disease in children under 5 years of age at Liaquat University Hospital, Hyderabad, Pakistan. Indian Heart J. 2014;66:145-9.

13. Karthiga S, Pathak S, Lazarus M. Clinical and anthropometric profile of congenital heart disease in children admitted in pediatric ward. Int J Scient Stu. 2017;5(5):112-7.

14. Hussain S, Sabir M, Afzal M, Asghar I. Incidence of congenital heart disease among neonates in a neonatal unit of a tertiary care hospital. J Pak Med Assoc. 2014:64(2):175-8.

15. Meshram RM, Gajimwar VS. Prevalence, profile, and pattern of congenital heart disease in Central India: A prospective, observational study. Nig J Cardiol. 2018;15:45-9.

16. Wanni KA, Shahzad N, Ashraf M, Ahmed K, Jan $M$, Rasool S. Prevalence and spectrum of congenital heart disease in children. Heart India. 2014;2:76-9.

17. Mahapatra A, Sarangi R, Mahapatra PP. Spectrum of congenital heart disease in a tertiary care centre of Eastern India. Int $\mathrm{J}$ Contemp Pediatr. 2017;4:314-6.

18. Jatav RK, Kumbhare MB, Srinivas M, Rao DR, Goutham Kumar P, Reddy PR, et al. Prevalence and pattern of congenital heart disease in Karimnagar, Andhra Pradesh, India: Diagnosed clinically and bytrans-thoracic-two-dimensional echocardiography. Int $\mathrm{J}$ Res Med Sci. 2014;2:186-92.

19. Liu Y, Chen S, Zühlke L, Black GC, Choy M, Li $\mathrm{N}$, et al. Global birth prevalence of congenital heart defects 1970-2017: updated systematic review and meta-analysis of 260 studies, Int $\mathrm{J}$ Epidemiol. 2019;48(2):455-63.

20. Bouma BJ, Mulder BJ. Changing landscape of congenital heart disease. Circ Res 2017;120:908-22.

21. van der Linde $D$, Konings $E E$, Slager $M A$, Witsenburg M, Helbing WA, Takkenberg JJ, et al. Birth prevalence of congenital heart disease worldwide: a systematic review and metaanalysis. J Am Coll Cardiol. 2011;58:2241-7.

22. Harshangi SV, Itagi LN, Patil V, Vijayanath V. Clinical study of congenital heart disease in infants in tertiary care hospital. J Pharm Sci Innov. 2013;2:15-8. 